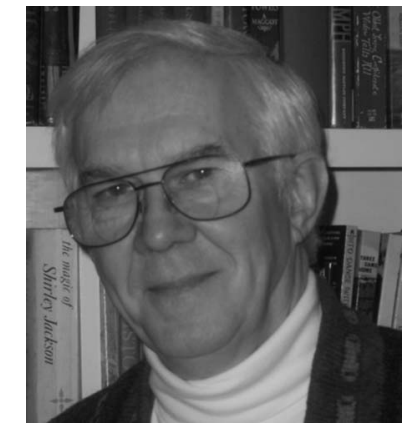

\section{7 in Review}

Each February I report to SPIE members and readers of this journal on its status. We live in a time of rapid improvement in the sophistication of recording data and generating sequential images derived from that data. These improvements are, for the most part, welcome and the journal is able to incorporate some of these advances as we publish your work in optical engineering. For example, color figures have become an accepted feature of the digital versions of the papers we publish.

This past year the SPIE journals staff, working with the American Institute of Physics, established the criteria for multimedia that can be attached to papers accepted for publication. Prior to this work, there was no way to transmit and archive ancillary audio and video data and results in a paper. Now, video files in QuickTime nonstreaming video (.qt or .mov), MPEG (.mpg), and DV (.dv) formats are accepted as part of the digital version of a paper. The preferred formats are .mov and .mpg. In the case of audio submissions, acceptable file formats for audio include PCM (.pcm), WAV (.wav), AIFF (.aif), and MP3 (.mp3) at $128 \mathrm{Kbs}$ or greater. Detailed specifications for both video and audio files are given at the bottom of the Web page on manuscript preparation on the SPIE Web site: http://spie.org/x1808.xml.

The balance of this report is intended to give you some idea of how an engineering journal is changing as torrents of information (some valid, some questionable, and some bogus) gush over your electronic doorstep. This past year the number of papers published in Optical Engineering declined slightly from last year's all-time high of 525 . This year 515 papers were published, a modest $2 \%$ decrease. For the past five years the number of papers that we have published (Table 1) has hovered around 500 with the exception of 2004, which appears to be an anomaly.

Last year there was one special section, Optical Metrology in the Transportation Industry, published in the May issue. As I stated in an earlier Year in Review, I believe the emphasis should be directed to attracting significant papers that will serve the community and that special section topics should be limited to areas that have not been strongly represented in the journal or are "hot" topics that our readers should be aware of. Proposals for specials are welcome and will be carefully considered.

While the greatest number of submitted papers in a year occurred in 2004 (Table 2), since then the submissions have stayed in the neighborhood of 900 papers. That's a lot of manuscripts! It means that I evaluate and assign Associate Editors to 18 papers every week. Whether this is good or bad, I cannot say. One of the cardinal rules of research publishing is that the author is free to send the paper to whatever journal will provide the best audience. So we have no control over the input.

After dropping to below 50\% acceptance rate in 2004, the ratio of accepted papers to those submitted rose dramatically to $63 \%$ in 2005 (Table 3). This past year the acceptance ratio is again below 50\%. I believe this may be due to efforts by the Board of Editors to tighten the standards for acceptable papers. The introduction of evaluation criteria instead of numerical ratings has, I think, provided a more even-handed assessment of the submitted papers by reviewers.

As with the regular submissions, the acceptance rate for $O E$ Letters has also declined-from $45 \%$ last year (Table 4) to $27 \%$ this year. In the case of OE Letters, my rough evaluation as the letters cross my desk is that this past year a number of authors were submitting papers, hoping that they would be rapidly published, but the papers were on of the same caliber as the regular submissions. Those authors whose papers do meet the stricter criteria for publishing an $O E$ Letter benefit not only from rapid publication (see Table 7 below), but also their papers will be published as Open Access documents, so that anyone visiting the SPIE Web site can download them.

As evidenced in Table 5, over the past few years there has been a dramatic increase in the papers published by authors from Asia, and a slow decline in papers from North America and Western Europe. Of the 515 papers published this year, again, more than half were written by Asian authors. But this past year there were no major changes in the distribution of papers between geographic regions.

Each year, I am pleased to be able to thank the SPIE journals staff. They are a conscientious group of women (you will find their names listed on the masthead of the journal), who with intelligence and a sense of fair play for authors and readers, move the manuscripts through the

Table 1 Major statistics for 2003-2007 and percentage changes from 2006.

\begin{tabular}{lcccccc}
\hline \hline & 2003 & 2004 & 2005 & 2006 & 2007 & $\begin{array}{c}2007 \text { vs } \\
2006\end{array}$ \\
\hline $\begin{array}{l}\text { Number of journal } \\
\text { pages }\end{array}$ & 3672 & 3164 & 3750 & 3920 & 3966 & $+1.17 \%$ \\
$\begin{array}{l}\text { Number of technical } \\
\text { pages }\end{array}$ & 3514 & 3023 & 3630 & 3802 & 3864 & $+1.63 \%$ \\
$\begin{array}{l}\text { Number of papers } \\
\text { published }\end{array}$ & 487 & 422 & 515 & 525 & 515 & $-1.91 \%$ \\
\hline \hline
\end{tabular}


Table 2 Regular and special section papers, received and published, for 2003-2007 and percentage changes from 2006 (including OE Letters).

\begin{tabular}{lccccccc}
\hline \hline & 2003 & 2004 & 2005 & 2006 & 2007 & 2007 ratio & 2007 vs 2006 \\
\hline Regular papers received & 781 & 912 & 875 & 826 & 879 & - & $+6.4 \%$ \\
Special papers received & 68 & 121 & 6 & 21 & 0 & - & $-100 \%$ \\
Regular papers published & 448 & 318 & 478 & 525 & 500 & $97 \%$ & $-4.8 \%$ \\
Special papers published & 39 & 104 & 37 & 0 & 15 & $3 \%$ & $1500 \%$ \\
\hline \hline
\end{tabular}

Table 3 Outcomes of papers acted on in 2004-2007 (regular papers only; OE Letters not included).

\begin{tabular}{lrrrrrrrr}
\hline \hline & \multicolumn{2}{c}{2004} & \multicolumn{2}{c}{2005} & \multicolumn{2}{c}{2006} & 2007 \\
\hline Accepted & 317 & $48.32 \%$ & 497 & $63.0 \%$ & 410 & $58.8 \%$ & 394 & $49.3 \%$ \\
Declined/Closed/Transferred & 331 & $50.46 \%$ & 287 & $36.4 \%$ & 279 & $40.0 \%$ & 399 & $49.9 \%$ \\
Withdrawn & 8 & $1.22 \%$ & 5 & $0.6 \%$ & 8 & $1.2 \%$ & 6 & $0.8 \%$ \\
Total & $\mathbf{6 5 6}$ & $\mathbf{1 0 0 \%}$ & $\mathbf{7 8 9}$ & $\mathbf{1 0 0 \%}$ & $\mathbf{6 9 7}$ & $\mathbf{1 0 0} \%$ & $\mathbf{7 9 9}$ & $\mathbf{1 0 0 \%}$ \\
\hline \hline
\end{tabular}

review process in a timely manner. They see that the authors remain informed and they chase down delinquent reviews. With a sense of fairness and concern for ethical publishing they serve as frontline detectors of plagiarism and double publication. This is accomplished through their experience handling many papers and from detecting telltale signals that plagiarizers can leave.

Table 6 provides an overview of the activity within the journals office for Optical Engineering. I am pleased to see that, although the number of reviewers we solicited was almost the same as last year, the number of reviews increased by more than $4 \%$.

Two measures that we monitor carefully are the length of time it takes to review a paper and the time to publish it. To an author, the only time that matters is the duration between submitting the paper and seeing it published. But the process consists of two distinct phases, review and publication. The first is determined chiefly by the reviewers, the second by the copy editing, typesetting, and printing process, although the latter does not have as large an effect now that a digital version of the paper is published on the Web as soon as the paper is ready.

Table 4 OE Letters statistics for 2004-2007.

\begin{tabular}{lccccc}
\hline \hline & 2004 & 2005 & 2006 & 2007 & $\%$ \\
\hline Letters received & 118 & 131 & 120 & 115 & \\
Letters published & 39 & 50 & 50 & 37 & \\
Accepted & 41 & 50 & 49 & 33 & $27.05 \%$ \\
Declined & 69 & 80 & 61 & 89 & $72.95 \%$ \\
\hline \hline
\end{tabular}

The review phase has dropped below 9 weeks for the first time since 2003. For that I am grateful. The longest time is that between the acceptance of a paper and its publication. Last year, this time increased by a month and a half. This was due to a limitation on the number of papers that can be included in an issue. This past year the backlog of publishable papers has been reduced by Managing Editor, Karolyn Labes. As can be seen in Table 7 the time from acceptance to publication of a paper has returned to that of previous years.

It's not often that I look at the comments provided by our reviewers. After all, as noted in Table 6, there were over 1600 of them this past year. But when I do, usually because of a particular editorial issue that needs to be

Table 5 Number of papers published by region of first author in 2004-2007.

\begin{tabular}{lrrrr}
\hline \hline Region & 2004 & 2005 & 2006 & 2007 \\
\hline Africa & 2 & 5 & 4 & 5 \\
Asia & 172 & 212 & 283 & 280 \\
Australia & 3 & 5 & 5 & 5 \\
Eastern Europe & 13 & 28 & 12 & 14 \\
Middle East & 14 & 10 & 15 & 7 \\
North America & 142 & 152 & 136 & 131 \\
South/Cent. America & 4 & 3 & 2 & 4 \\
Western Europe & 72 & 100 & 68 & 69 \\
\hline \hline
\end{tabular}


Table 6 Activity of the editorial office in 2006 and 2007 (regular papers only, including $O E$ Letters).

\begin{tabular}{|c|c|c|c|c|}
\hline & $\begin{array}{c}2006 \\
\text { Numbers }\end{array}$ & $\begin{array}{l}\text { Change } \\
\text { vs } \\
2005\end{array}$ & $\begin{array}{c}2007 \\
\text { Numbers }\end{array}$ & $\begin{array}{c}\text { Change } \\
\text { vs } \\
2006\end{array}$ \\
\hline Reviewers solicited & 4029 & $-26.3 \%$ & 3989 & $-0.99 \%$ \\
\hline Reviews received & 1564 & $-20.3 \%$ & 1632 & $+4.35 \%$ \\
\hline $\begin{array}{l}\text { Revised } \\
\text { manuscripts } \\
\text { received }\end{array}$ & 604 & $-17.0 \%$ & 537 & $-11.09 \%$ \\
\hline $\begin{array}{l}\text { Papers returned } \\
\text { to authors } \\
\text { for revision }\end{array}$ & 642 & $-8.6 \%$ & 513 & $-20.09 \%$ \\
\hline
\end{tabular}

addressed, I am invariably impressed by the care and thoughtfulness of the reviews. Most reviewers, while critical, provide suggestions for improving the paper and suggest additional references to assist the authors. I thank all of those 1600 plus reviewers for your efforts to uphold our standards of originality and significance that we require. I hope you will continue to assist us in the future.

I want to thank the members of the Board of Editors for their contributions toward maintaining these standards. Their names and affiliations are also listed on the
Table 7 Journal performance for reviews and publication time.

\begin{tabular}{|c|c|c|c|c|c|}
\hline & 2003 & 2004 & 2005 & 2006 & 2007 \\
\hline \multicolumn{6}{|c|}{ Average time for review (weeks): } \\
\hline Regular papers & 8.4 & 11.4 & 9.5 & 9.8 & 8.7 \\
\hline OE Letters & 4.4 & 6.7 & 5.1 & 5.0 & 4.4 \\
\hline \multicolumn{6}{|c|}{$\begin{array}{l}\text { Average time acceptance to } \\
\text { publication (months): }\end{array}$} \\
\hline Regular papers & 5.8 & 5.6 & 5.8 & 7.4 & 6.1 \\
\hline OE Letters & 3.2 & 3.4 & 2.3 & 2.4 & 2.8 \\
\hline
\end{tabular}

masthead. I thank Pete Martin for serving as Associate Editor in the area of thin films. Alan Stewart of Boeing will be replacing him. I also thank Keith Krapels who oversaw radiometry and IR systems. Rich Vollmerhausen, who recently retired from the Night Vision Lab, has taken over in that area. I am fortunate to be able to work with such a distinguished group of people. Thank you all.

Donald C. O'Shea Editor 